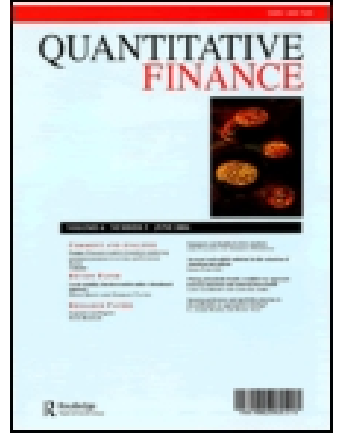

Quantitative Finance

ISSN: 1469-7688 (Print) 1469-7696 (Online) Journal homepage: http://www.tandfonline.com/loi/rquf20

\title{
Systematic risk and timescales
}

\section{Ramazan Gen,ay , Faruk Sel,uk \& Brandon Whitcher}

To cite this article: Ramazan Gen, ay, Faruk Sel, uk \& Brandon Whitcher (2003) Systematic risk and timescales, Quantitative Finance, 3:2, 108-116, DOI: 10.1088/1469-7688/3/2/305

To link to this article: https://doi.org/10.1088/1469-7688/3/2/305

曲 Published online: 19 Aug 2006.

Submit your article to this journal

Џll Article views: 478

Citing articles: 94 View citing articles $\square$ 


\title{
Systematic risk and timescales
}

\author{
Ramazan Gençay ${ }^{1,2,5}$, Faruk Selçuk ${ }^{3}$ and Brandon Whitcher ${ }^{4}$ \\ ${ }^{1}$ Department of Economics, University of Windsor, 401 Sunset Avenue, \\ Windsor, ON N9B 3P4, Canada \\ ${ }^{2}$ HEC Genève, Faculté des Sciences Economiques et Sociales Uni \\ Mail-Boulevard du Pont-d'Arve 40, CH-1211 Genève 4, Switzerland \\ ${ }^{3}$ Department of Economics, Bilkent University, Bilkent 06533, Ankara, \\ Turkey and Colorado College, Colorado Springs, CO 80903, USA \\ ${ }^{4}$ Geophysical Statistics Project, National Center for Atmospheric Research, \\ PO Box 3000, Boulder, CO 80307-3000, USA \\ E-mail: gencay@uwindsor.ca, faruk@bilkent.edu.tr and whitcher@ucar.edu
}

Received 1 April 2002, in final form 9 January 2003

Published 13 March 2003

Online at stacks.iop.org/Quant/3/108

\begin{abstract}
In this paper we propose a new approach to estimating the systematic risk (the beta of an asset) in a capital asset pricing model (CAPM). The proposed method is based on a wavelet multiscaling approach that decomposes a given time series on a scale-by-scale basis. At each scale, the wavelet variance of the market return and the wavelet covariance between the market return and a portfolio are calculated to obtain an estimate of the portfolio's beta. The empirical results show that the relationship between the return of a portfolio and its beta becomes stronger as the wavelet scale increases. Therefore, the predictions of the CAPM model are more relevant in the medium long run as compared to short time horizons.
\end{abstract}

\section{Introduction}

In its simplest form, the capital asset pricing model (CAPM) predicts that the excess return of a stock (return over the riskless rate of return) should be proportional to the market premium (market return over the riskless rate of return) ${ }^{6}$. Early empirical studies on the CAPM such as Black et al (1972) and Fama and MacBeth (1973) were supportive of the implications of the model. That is, the average return of high beta stocks was higher than the average return of low beta stocks. Furthermore, the relationship was roughly linear, although the slope was too flat to support the CAPM strongly (Campbell 2000).

Amongst many others, some studies of beta estimations concentrated on the stability of beta over time (Harvey 1989), the borrowing constraints (Black 1972), the impact of structural change and regime switches (Garcia and Ghysels

5 Author to whom any correspondence should be addressed.

6 The proportionality factor is known as the 'systematic risk' or the 'beta' of an asset. See Campbell (2000) and Cochrane (1999) for a survey of the recent developments in the finance literature in general and asset pricing in particular.
1998), the effect of world markets and volatility (Bekaert and Harvey 1995, 1997, Harvey 1991), non-synchronous data issues (Scholes and Williams 1977), the time horizon of investors (Levhari and Levy 1977) and the impact of return interval (Brailsford and Faff 1997, Brailsford and Josev 1997, Cohen et al 1986, Frankfurter et al 1994, Hawawini 1983, Handa et al 1989, 1993). The studies on the impact of return interval on beta estimates point out the importance of the timescale issue. An early study by Levhari and Levy (1977) shows that if the analyst uses a time horizon shorter than the true one, the beta estimates are biased. Fama (1980, 1981) provides evidence that the power of macroeconomic variables in explaining the stock prices increases with increasing time length. Handa et al (1989) report that different beta estimates are possible for the same stock if different return intervals are considered. Similarly, Handa et al (1993) reject the CAPM when monthly returns are used but fail to reject the CAPM if the yearly return interval is employed. Cohen et al (1986) and references therein provide ample evidence that the beta estimates are sensitive to return intervals. By using Australian 

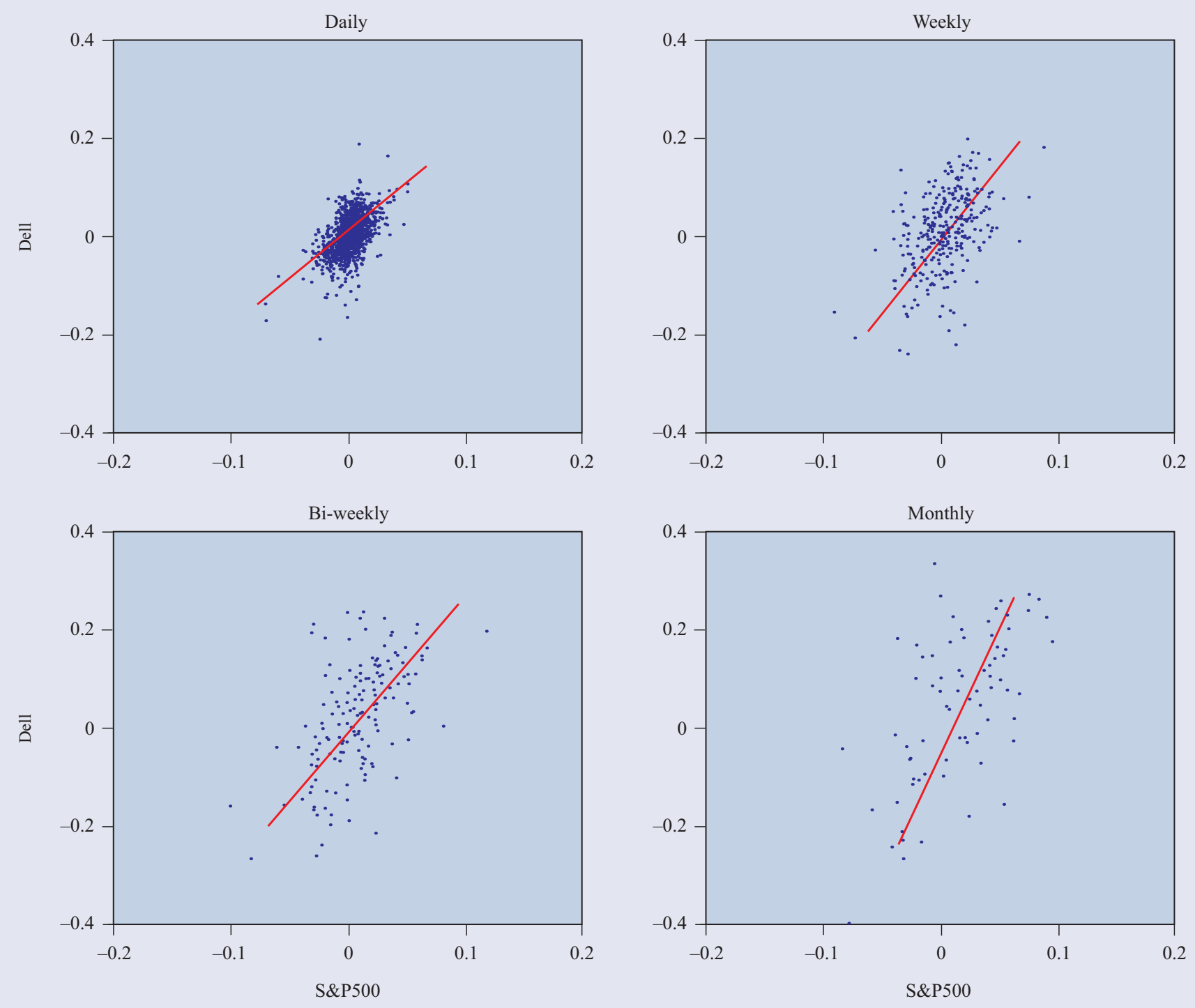

Figure 1. Dell stock return (vertical axis) versus S\&P500 return, measured at different time periods. Notice that the relation between a stock return (Dell) and the market (S\&P500) differs if the estimation is made with daily, weekly, bi-weekly or monthly data. The estimated beta of the stock (Dell) increases from 1.70 (daily) to 2.41 (monthly) as the time horizon increases. Sample period is 2 January 1995-2 January 2001 (1511 days).

equity market data, Brailsford and Faff (1997) report that the CAPM model (with a GARCH-M specification) is supported for weekly and monthly interval returns while the greatest support is found in the weekly return intervals. The daily return interval in that study does not support the CAPM.

To illustrate the effect of different time intervals on beta estimation, we chose a stock (Dell) from the US market and calculated its beta at different time horizons. The return of Dell versus S\&P500 is presented in figure 1 for different time horizons. The estimated beta of the stock increased from 1.70 (daily) to 2.41 (monthly) with increased time intervals ${ }^{7}$. This example shows that it makes a difference if one employs daily, weekly or monthly data to estimate systematic risk. Notice

7 The data source is the Datastream. The 90 day treasury bill is assumed to be the risk-free return asset in beta estimation. Sample period is 2 January 1995-2 January 2001 (1511 days). that when the return interval is increased in a given sample period, the number of sample points decreases, which results in loss of information.

It is not only the time interval which makes a difference in beta estimation, but also the sampling rule employed to construct a particular time series. For example, in constructing a monthly time series from daily data, the last business day of each month might be accepted as a representative of that month. However, there is no reason why the day before the last business day of each month should not be a representative day or two business days before the last business day and so on. Figure 2 gives a stock's (Dell) monthly beta estimates by sampling different days of the month. The first day on the horizontal axis represents the last business day of each month, the second day is the business day before the last business day of the month and so on. The last day represents 18 business 


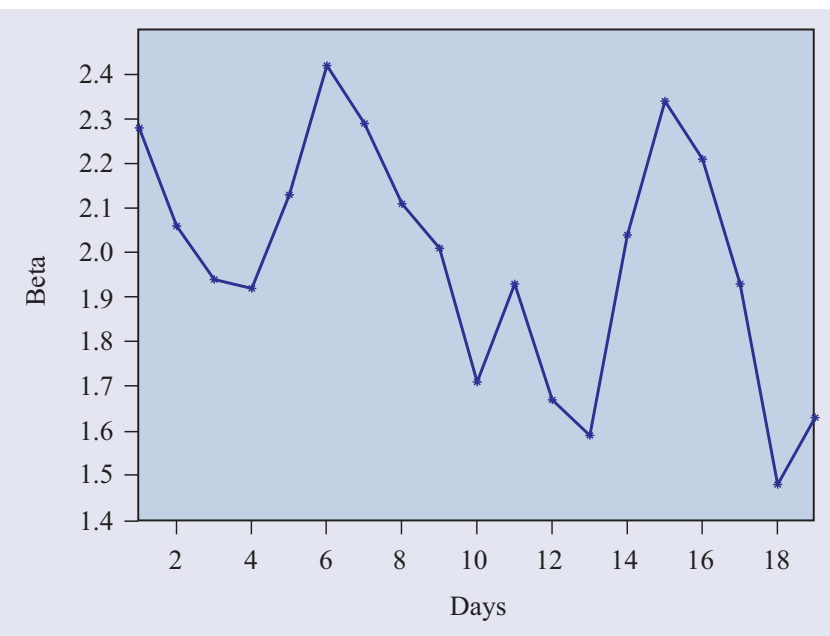

Figure 2. A stock's (Dell) monthly beta estimates by sampling different days of the month. The first day on the horizontal axis represents the last business day of each month, the second day is the business day before the last business day of the month and so on. The last day represents 18 business days before the last day of each month. Sample period is 2 January 1995-2 January 2001 (72 months).

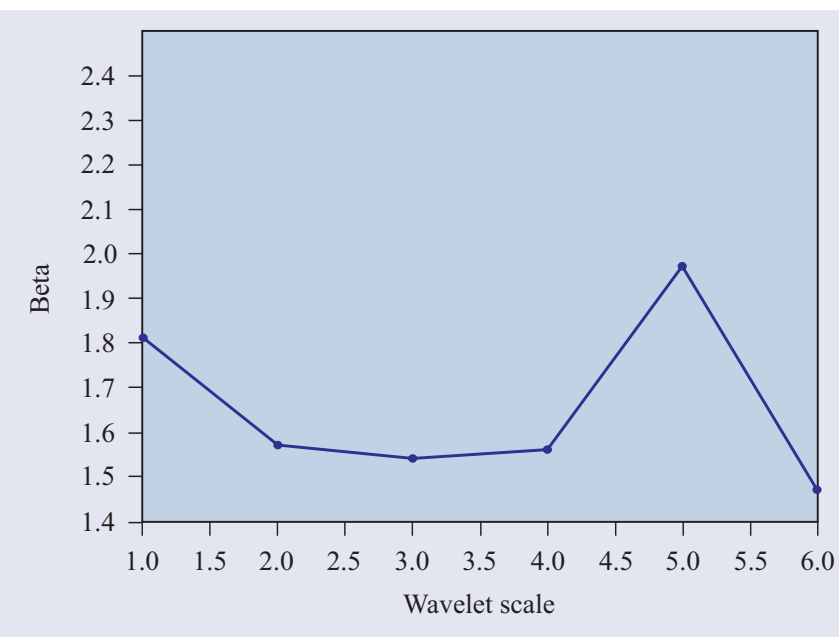

Figure 3. Wavelet estimate of a stocks' beta (Dell) at different timescales. The wavelet scales are such that scale 1 captures dynamics with 2-4 day period, scale 2 with $4-8$ day period dynamics, scale 3 with $8-16$ day period dynamics, scale 4 with 16-32 day period dynamics, scale 5 with 32-64 day period dynamics and scale 6 with 64-128 day period dynamics. Sample period is 2 January 1995-2 January 2001 (1511 days).

days before the last day of each month. The sample period is 2 January 1995-2 January 2001 (72 months). It is clear that the estimated monthly beta widely fluctuates as a function of the day of the month. Notice that some of the estimated betas significantly differ from others.

In this paper, we propose a new approach to estimating the systematic risk (beta) in the CAPM. The proposed method is based on wavelet analysis which enables us to decompose a time series measured at the highest possible frequency into different timescales. Hence, it provides a natural platform to investigate the beta behaviour (systematic risk) at different time horizons without losing any data points. As an example of the proposed approach, figure 3 plots wavelet estimates of a stock's beta (Dell) at different timescales. The wavelet scales are such that scale 1 captures dynamics with a $2-4$ day period, scale 2 with 4-8 day period dynamics, scale 3 with $8-16$ day period dynamics, scale 4 with 16-32 day period dynamics, scale 5 with 32-64 day period dynamics and scale 6 with 64-128 day period dynamics. Sample period is 2 January 1995-2 January 2001 (1511 days).

The empirical results show that the relationship between the return of a portfolio and its beta becomes stronger as the scale increases. Therefore, the predictions of the CAPM are more relevant at a medium long run horizon as compared to short time horizons. The weak relation between the return of a portfolio and its beta at lower scales is probably caused by low signal-to-noise ratio at these scales. The existence of noise traders (traders selling or buying stock for non-fundamental reasons) and other anomalies such as infrequent trading and bid-ask bounce might be some of the reasons behind this low signal-to-noise ratio.

This paper is structured as follows. The CAPM model is presented in section 2. The wavelet multiscale analysis, the wavelet variance and covariance are presented in section 3 . The multiscale beta estimation with S\&P500 stocks is studied in section 4 . We conclude in section 5 .

\section{Capital asset pricing model (CAPM)}

The CAPM naturally arises from the utility maximization problem of a representative agent ${ }^{8}$. Consider a consumer with a horizon of $T$ periods who wants to maximize the present discounted value of expected utility:

$$
\max E_{0}\left[\sum_{t=0}^{T-1} \frac{1}{(1+\theta)^{t}} U\left(c_{t}\right)\right],
$$

where $E_{0}$ denotes expectation conditional on information at time zero, $\theta$ is the subjective rate of time preference, $U(\cdot)$ is the utility function and $c_{t}$ is consumption. Suppose that the consumer can allocate his wealth among $(n-1)$ risky assets with an $r_{i t}$ rate of return and a riskless asset with a rate of return $r_{0 t}$. The maximization results in $n$ first-order conditions in the following form:

$$
U^{\prime}\left(c_{t}\right)=\frac{E\left[U^{\prime}\left(c_{t+1}\right)\left(1+r_{i t}\right)\right]}{1+\theta}, \quad i=0, \ldots, n-1 .
$$

These first-order conditions show that the consumer must choose a consumption path such that the marginal utility of consumption for this period must be equal to the discounted expected marginal utility of the consumption for the next period. The first-order conditions must hold regardless of the characteristics of the assets, whether they are risky or riskless. By rearranging the first-order conditions in equation (2),

$$
E\left[U^{\prime}\left(c_{t+1}\right)\left(r_{i t}-r_{0 t}\right)\right]=0, \quad i=1, \ldots, n-1,
$$

8 See Blanchard and Fischer (1989, ch 10) and Gençay et al (2001a, ch 3). 
which may be rewritten as

$$
\begin{gathered}
E\left[U^{\prime}\left(c_{t+1}\right)\right] E\left[r_{i t}-r_{0 t}\right]+\operatorname{Cov}\left[U^{\prime}\left(c_{t+1}\right), r_{i t}\right]=0, \\
i=1, \ldots, n-1 .
\end{gathered}
$$

At equilibrium, the return from asset $i$ must satisfy the following equation:

$$
E\left(r_{i t}\right)=r_{0 t}-\frac{\operatorname{Cov}\left[U^{\prime}\left(c_{t+1}\right), r_{i t}\right]}{E\left[U^{\prime}\left(c_{t+1}\right)\right]}, \quad i=1, \ldots, n-1 .
$$

According to equation (5), the investor will invest in an asset with an expected rate of return less than the risk free rate of return if the asset return has a positive relationship with the marginal utility of consumption. This is because the asset is a hedging tool for consumption smoothing as it provides a higher rate of return when the marginal utility of consumption is high and a lower rate of return when the marginal utility of consumption is low ${ }^{9}$.

Suppose that there exists an asset $m$ such that its return is negatively related with the marginal utility of consumption in the next period so that $U^{\prime}\left(c_{t+1}\right)=-\gamma r_{m t}$ for some positive $\gamma$. It follows that

$$
\operatorname{Cov}\left[U^{\prime}\left(c_{t+1}\right), r_{i t}\right]=-\gamma \operatorname{Cov}\left(r_{i t}, r_{m t}\right) .
$$

Equation (5) must hold for asset $m$ as well. Therefore,

$$
E\left(r_{m t}\right)=r_{0 t}-\frac{\operatorname{Cov}\left[U^{\prime}\left(c_{t+1}\right), r_{m t}\right]}{E\left[U^{\prime}\left(c_{t+1}\right)\right]}
$$

or

$$
E\left(r_{m t}\right)=r_{0 t}+\frac{\gamma \sigma_{m}^{2}}{E\left[U^{\prime}\left(c_{t+1}\right)\right]},
$$

where $\sigma_{m}^{2}$ is the return variance for asset $m$. It follows that

$$
E\left(r_{i t}\right)=r_{0 t}+\left[\frac{\operatorname{Cov}\left(r_{i t}, r_{m t}\right)}{\sigma_{m}^{2}}\right]\left[E\left(r_{m t}\right)-r_{0 t}\right] .
$$

Notice that the return from asset $m$ is assumed to be negatively correlated with the marginal utility of consumption in the next period. If we assume that $m$ is the market portfolio (all traded assets in the market), equation (9) is known as the security market line in the CAPM of Sharpe (1964) and Lintner (1965). Equation (9) implies that the excess return from asset $i$ (in excess of the risk free asset return) should be proportional to the market premium (market return in excess of the risk free asset return). The proportionality factor is known as systematic risk, or the beta of an asset,

$$
\beta_{i}=\frac{\operatorname{Cov}\left(r_{i t}, r_{m t}\right)}{\sigma_{m}^{2}} .
$$

In empirical finance, the usual estimator for the beta is the OLS estimate from the following regression:

$$
\left(r_{i t}-r_{0 t}\right)=\beta_{i}\left(r_{m t}-r_{0 t}\right)+\epsilon_{i t}
$$

where $\epsilon_{i t}$ is the white noise disturbance term. We now propose an alternative multiscale estimator for the systematic risk or beta of an asset in equation (10).

9 Because of the diminishing marginal utility assumption, the marginal utility of consumption is high when the level of consumption is low and the marginal utility of consumption is low when the level of consumption is high.

\section{Wavelets}

Wavelet filters provide an easy vehicle to study the multiresolution properties of a process. It is important to realize that economic/financial time series may not need to follow the same relationship as a function of time horizon (scale). Hence, a transform that decomposes a process into different time horizons is appealing as it differentiates seasonalities, reveals structural breaks and volatility clusters and identifies local and global dynamic properties of a process at these timescales.

With respect to economics and finance, the works of Ramsey and co-authors first introduced wavelets into mainstream literature. Ramsey and Zhang (1997) performed a time-frequency analysis of foreign exchange rates using wavelets. They found that wavelet analysis succinctly captured a variety of nonstationary events in the series. Ramsey and Lampart (1998a, 1998b) decomposed economic variables across several wavelet scales in order to identify different relationships between money and income, and between consumption and income. See Ramsey (1999) for a recent review article on wavelets in economics and finance.

Gençay et al (2001a) presented a general framework for the basic premise of wavelet filtering within the context of economic/financial time series. The authors illustrate that a number of concepts such as nonstationarity, multiresolution and approximate decorrelation emerge from wavelet filters. Wavelet filtering provides a natural platform to deal with the time-varying characteristics found in most financial time series, and thus the assumption of stationarity may be avoided. Gençay et al (2001b) proposed a simple method for intraday seasonality extraction that is free of model selection parameters. Their methodology is based on a wavelet multiscaling approach which decomposes the data into its low and high frequency components. Gençay et al (2001c) investigated the scaling properties of foreign exchange volatility through a multiscale decomposition of the variance and covariance between two time series on a scale-by-scale basis. It is shown that foreign exchange rate volatilities follow different scaling laws at different horizons.

\subsection{Multiscale analysis}

The economy consists of several agents with different time horizons when it comes to making a consumption-saving decision. Therefore, the predictions of the CAPM model should be investigated at different timescales. The different estimates of beta for the same asset at different return intervals documented in the empirical research probably reflects this fact $^{10}$. Wavelet analysis is a natural tool used to investigate different timescale properties of beta as it enables us to decompose returns on a scale-by-scale basis.

Unlike the Fourier transform, which uses sine and cosine functions to project the data on, the wavelet transform utilizes a wavelet function that oscillates on a short interval of time. The Haar wavelet is a simple example of a wavelet function that

${ }^{10}$ Bjornson et al (1999) investigate the influence of low and high frequency macroeconomic forces on asset pricing and show that different frequency dynamics have different effects on the systematic risk. 
may be used to obtain a multiscale decomposition of a return series. The Haar wavelet filter coefficient vector, of length $L=2$, is given by $h=\left(h_{0}, h_{1}\right)=(1 / \sqrt{2},-1 / \sqrt{2})$. Three basic properties characterize a wavelet filter ${ }^{11}$ :

$$
\sum_{l} h_{l}=0, \quad \sum_{l} h_{l}^{2}=1
$$

and

$$
\sum_{l} h_{l} h_{l+2 n}=0 \quad \text { for all integers } n \neq 0 .
$$

That is, the wavelet filter sums to zero, has unit energy and is orthogonal to its even shifts. These properties are easily verified for the Haar wavelet filter. The first property guarantees that $h$ is associated with a differencing operation and thus identifies changes in the data. The second ensures that the coefficients from the wavelet transform will have the same energy as the data, where energy is defined to be the sum of squares. Thus, no extra information has been added through the wavelet transform nor has any information been excluded. The third property allows for efficient construction of an orthogonal transform and therefore efficient implementation on a computer. The complementary filter to $h$ is the Haar scaling filter $g=\left(g_{0}, g_{1}\right)=(1 / \sqrt{2}, 1 / \sqrt{2})$, which possesses the following attributes:

$$
\begin{array}{cl} 
& \sum_{l} g_{l}=\sqrt{2}, \quad \sum_{l} g_{l}^{2}=1, \\
\text { and } \quad & \sum_{l} g_{l} g_{l+2 n}=0 \quad \text { for all integers } n \neq 0 .
\end{array}
$$

The scaling filter follows the same orthonormality properties of the wavelet filter, unit energy and orthogonality to even shifts, but instead of differencing consecutive blocks of observations the scaling filter averages them. Thus, $g$ may be viewed as a local averaging operator. Additional information regarding wavelet filters, including the Haar and longer compactly supported orthogonal wavelets, and their properties may be found in, for example, Mallat (1998) and Gençay et al (2001a).

The Haar wavelet filter coefficients $h$, when applied to a return series $r_{t}$, produce the following wavelet coefficients:

$$
\sqrt{2} \tilde{w}_{1 t}=h_{0} r_{t}+h_{1} r_{t-1}, \quad t=0,1, \ldots, T-1 .
$$

The factor of $\sqrt{2}$ is necessary to guarantee that the squared norm of the wavelet coefficients is equivalent to the squared norm of the return series. We do not reference a particular asset with $r_{t}$ in equation (14) in order to simplify notation. Thus, the wavelet coefficient $\tilde{w}_{1 t}$ is a weighted difference between consecutive returns. The Haar scaling filter coefficient vector $g$ is used to produce the scaling coefficients

$$
\sqrt{2} \tilde{v}_{1 t}=g_{0} r_{t}+g_{1} r_{t-1}, \quad t=0,1, \ldots, T-1 .
$$

In contrast to $\tilde{w}_{1}$, the scaling coefficients $\tilde{v}_{1}$ are based on local averages (of length two) of the original returns. By collecting both sets of coefficients into $\tilde{w}=\left(\tilde{w}_{1}, \tilde{v}_{1}\right)$, we have separated

${ }^{11}$ We are specifically concerned with the Haar and other compactly supported orthogonal wavelets such as those of Daubechies (1992). (or filtered) the high frequency and low frequency content from the original returns.

The wavelet coefficients $\tilde{w}_{1}$ are associated with the high frequency content of the returns $r_{t}$. By the spectral representation theorem, the spectrum of $r_{t}$ contains all frequencies between zero and $1 / 2$ cycles per time unit $\Delta t$. The wavelet coefficients $\tilde{w}_{1}$ are therefore associated with the frequencies in the interval $[1 / 4,1 / 2]$. We can apply the convolutions in equations (14) and (15) to the scaling coefficients $\tilde{v}_{1}$ (instead of the returns $r_{t}$ ) in order to produce the wavelet coefficients $\tilde{w}_{2}$ associated with the frequency interval $[1 / 8,1 / 4]$, and scaling coefficients $\tilde{v}_{2}$ associated with the frequency interval $[0,1 / 8]$. This procedure may be repeated up to the level $J \leqslant \log _{2} T$ with the resulting wavelet and scaling coefficients organized into the vector $\tilde{w}=\left(\tilde{w}_{1}, \tilde{w}_{2}, \ldots, \tilde{w}_{J}, \tilde{v}_{J}\right)$. The wavelet coefficients from level $j=1,2, \ldots, J$ are associated with the frequency interval $\left[1 / 2^{(j+1)}, 1 / 2^{j}\right]$ while the remaining scaling coefficients $\tilde{v}_{J}$ are associated with the remaining frequencies $\left[0,1 / 2^{(j+1)}\right]$.

The procedure of filtering output from a previous filtering operation is known as a filter cascade and allows one to relate the final filtered series to the original series via a single filter. We explore this connection using the Haar wavelet filter. Let us define a filter $h^{\prime}=\left(h_{0}, 0, h_{1}\right)$ to be the Haar wavelet filter with a zero between the two coefficients. The level 2 Haar wavelet filter is given by ${ }^{12}$

$$
h_{2, t}=\left\{g * h_{t}^{\prime}\right\}=\sum_{u=0}^{L-1} g_{u} h_{t-u}^{\prime}, \quad t=0, \ldots, 3,
$$

so that $h_{2}=(1 / 2,1 / 2,-1 / 2,-1 / 2)$ and has length $L_{2}=$ $3 L-2=4$. Instead of the recursive procedure described above, the wavelet coefficients $\tilde{w}_{2}$ may be obtained using $h_{2}$ via $2 \tilde{w}_{2}=\left\{h_{2} * r_{t}\right\}$ (the factor of two is a normalization constant). The level 2 Haar wavelet filter first averages two pairs of returns from $r_{t}$ and then proceeds to difference them. Thus, the wavelet coefficients $\tilde{w}_{2}$ are associated with changes on a scale of two. By defining $g^{\prime}=\left(g_{0}, 0, g_{1}\right)$, the level 2 Haar scaling filter is

$$
g_{2, t}=\left\{g * g_{t}^{\prime}\right\}=\sum_{u=0}^{L-1} g_{u} g_{t-u}^{\prime}, \quad t=0, \ldots, 3,
$$

so that $g_{2}=(1 / 2,1 / 2,1 / 2,1 / 2)$. We see that $g_{2}$ is a simple average of four consecutive returns from $r_{t}$. The scaling coefficients $\tilde{v}_{2}$ may be obtained directly using $g_{2}$ via $2 \tilde{v}_{2}=$ $\left\{g_{2} * r_{t}\right\}$. Higher scales of wavelet and scaling filter coefficients may be obtained by convolving the length $L=2$ filters $h$ and $g$ with increasing numbers of zeros inserted between coefficients. For example, let $h^{\prime \prime}=\left(h_{0}, 0,0, h_{1}\right)$ and define the level 3 Haar wavelet filter to be $h_{3}=\left\{\left\{g * g_{t}^{\prime}\right\} * h_{t}^{\prime \prime}\right\}$ with coefficients

$$
h_{3}=\left(\frac{1}{\sqrt{8}}, \frac{1}{\sqrt{8}}, \frac{1}{\sqrt{8}}, \frac{1}{\sqrt{8}}, \frac{-1}{\sqrt{8}}, \frac{-1}{\sqrt{8}}, \frac{-1}{\sqrt{8}}, \frac{-1}{\sqrt{8}}\right),
$$

12 The convolution operator defined by $c_{t}=\left\{a * b_{t}\right\}$ assumes an infinite sequence of coefficients, but since all but a few coefficients from wavelet filters are non-zero we choose to only include those indices that produce non-zero coefficients. 
with length $L_{3}=7(L-1)+1$. In general, the length of a level $j$ wavelet filter is given by $L_{j}=\left(2^{j}-1\right)(L-1)+1$ from the successive applications of the convolution operator. If we convolve $h_{3}$ with $r_{t}$ it is clear that averages of length four are applied to consecutive blocks of returns and then those consecutive blocks are differenced, thus the wavelet coefficients $\sqrt{8} \tilde{w}_{3}=\left\{h_{3} * r_{t}\right\}$ are associated with changes on a scale of four returns. If we construct the level 3 Haar scaling filter $g_{3}=\left\{\left\{g * g_{t}^{\prime}\right\} * g_{t}^{\prime \prime}\right\}$, with coefficients

$$
g_{3}=\left(\frac{1}{\sqrt{8}}, \frac{1}{\sqrt{8}}, \frac{1}{\sqrt{8}}, \frac{1}{\sqrt{8}}, \frac{1}{\sqrt{8}}, \frac{1}{\sqrt{8}}, \frac{1}{\sqrt{8}}, \frac{1}{\sqrt{8}}\right),
$$

we observe an average of eight consecutive blocks of returns. The filter cascade procedure may be repeated by forming filters with more and more zeros inserted between filter coefficients.

The interpretation of wavelet coefficients as the difference of averages formed using $2^{j-1}$ returns is natural when using the Haar wavelet filter. Likewise, scaling coefficients are a straightforward average of $2^{j}$ returns. When decomposing $r_{t}$ using the wavelet transform, we are actually separating layers of information associated with different timescales that increase with the level of the transform. Although beyond the scope of this paper, longer wavelet filters ${ }^{13}$ also retain this interpretation as the difference of averages. After the wavelet coefficient vector associated with changes at the longest timescale, the remaining information is captured in the scaling coefficients.

\subsection{Wavelet variance and covariance}

An important characteristic of the wavelet transform is its ability to decompose (analyse) the variance of a time series. When discussing the wavelet transform in the previous section, we pointed out that a vector of wavelet coefficients is associated with changes at a particular scale. This means that each wavelet coefficient was constructed using a difference of two (weighted) averages. Applying the wavelet transform to a return series produces a decomposition on a scale-by-scale basis.

If we assume that dependence structure of our return $r_{m t}$ is independent of time (this is true for stationary time series), then we may define the time-independent wavelet variance, or just the wavelet variance, of asset $m$ associated with level $j$ to be

$$
\sigma_{m j}^{2}=\operatorname{Var}\left(\tilde{w}_{m j}\right)
$$

That is, the level $j$ wavelet variance is simply the variance of the wavelet coefficients at that level and may be estimated using all wavelet coefficients not affected by the boundary (Gençay et al 2001a, ch 7).

Let $r_{m t}$ and $r_{n t}$ be the return from two distinct assets $m$ and $n$. We obtain a wavelet decomposition for each asset by applying the wavelet transform to $r_{m t}$ and $r_{n t}$ individually, yielding the wavelet coefficient vectors $\tilde{w}_{m}$ and $\tilde{w}_{n}$, respectively. The wavelet covariance between $r_{m t}$ and $r_{n t}$ for level $j$ is given by $\operatorname{Cov}\left(\tilde{w}_{m j}, \tilde{w}_{n j}\right)$ and unbiased estimation

13 The compactly supported wavelet filters of Daubechies (1992) have been widely used. is provided in Gençay et al (2001a, ch 7). The decomposition of covariance between $r_{m t}$ and $r_{n t}$ is valid provided one uses the wavelet transform outlined in the previous section.

\section{Empirical results}

Our data set consists of all the stocks listed in the S\&P500 index between 1 January 1973 and 1 November 2000 for portfolio construction purposes. The corresponding market portfolio is taken to be the S\&P500 index. The risk free rate of return $r_{0 t}$ is assumed to be the daily rate of return from the 90 day treasury bill $^{14}$. The sample size is 7263 days (roughly 28 years).

The daily return of each stock is calculated as the log price difference

$$
r_{i t}=\log P_{i t}-\log P_{i t-1},
$$

where $P_{i t}$ is the price of asset $i$ at day $t$. The market return, $r_{m t}$, is taken as the log difference of the S\&P500 index

$$
r_{m t}=\log S_{t}-\log S_{t-1},
$$

where $S_{t}$ is the index value at day $t$. During the entire sample period, the beta of each individual stock is calculated from a one year subsample using the wavelet beta estimator $\beta_{i j}^{w}$ utilizing the $\operatorname{LA}(8)$ wavelet filter ${ }^{15}$ for scales $j=1,2 \ldots, 6$ :

$$
\beta_{i j}^{w}=\frac{\operatorname{Cov}\left(\tilde{w}_{m j}, \tilde{w}_{i j}\right)}{\sigma_{m j}^{2}},
$$

where $\sigma_{m j}^{2}=\operatorname{Var}\left(\tilde{w}_{m j}\right)$ is the wavelet variance of the market premium (the difference between market return $r_{m t}$ and the risk free return $r_{0 t}$, see equation (11)) at the wavelet scale $j$ and $\operatorname{Cov}\left(\tilde{w}_{m j}, \tilde{w}_{i j}\right)$ is the wavelet covariance at wavelet scale $j$ between the individual stock premium (the difference between return $r_{i t}$ and the risk free return $r_{0 t}$ ) and the market premium. Since we employ daily data in our analysis, wavelet scales are such that scale 1 is associated with $2-4$ day period dynamics, scale 2 with $4-8$ day period dynamics, scale 3 with 8-16 day period dynamics, scale 4 with 16-32 day period dynamics, scale 5 with 32-64 day period dynamics and scale 6 with 64-128 day period dynamics. Since the portfolio updating is carried out every year, scale 6 is the highest scale at which we can calculate the beta of each stock because scale 7 corresponds to 128-256 day dynamics (approximately one year).

Each year in the sample period, the stocks are ranked at each scale according to their estimated wavelet betas. From these rankings, ten (and 15) portfolios with equal numbers of stocks are constructed such that the first portfolio consists of stocks with the lowest betas while the last portfolio contains the stocks with the highest betas. The return from each portfolio (stocks are equally weighted in each portfolio) during the following year is calculated and the portfolio beta with the corresponding average return is stored at each scale. This process (updating portfolios every year according to beta sizes,

${ }^{14}$ Data source for individual stocks and the S\&P500 index (adjusted for dividends) is the Datastream. The 90 day yield is obtained from the H.15 Release, Federal Reserve Board of Governors.

${ }^{15}$ We denote the Daubechies least asymmetric wavelet filter of length $L$ as $\mathrm{LA}(L)$. 
(a)

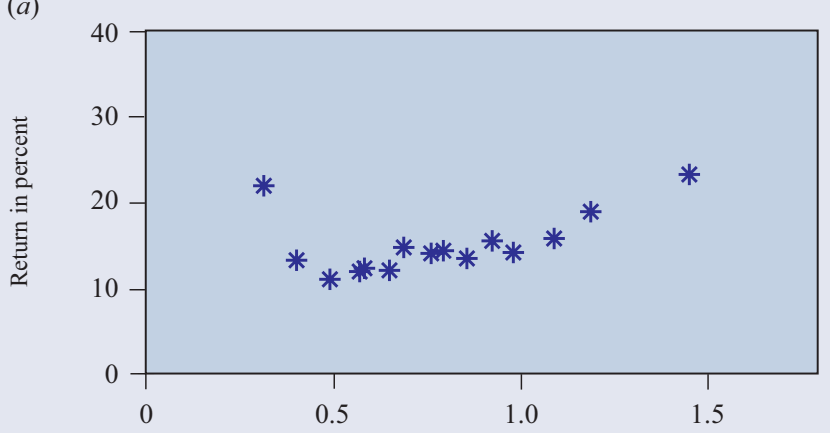

(c)

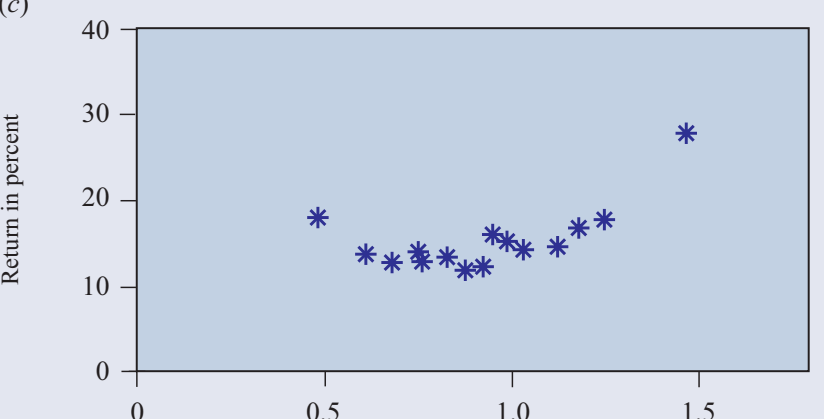

(e)

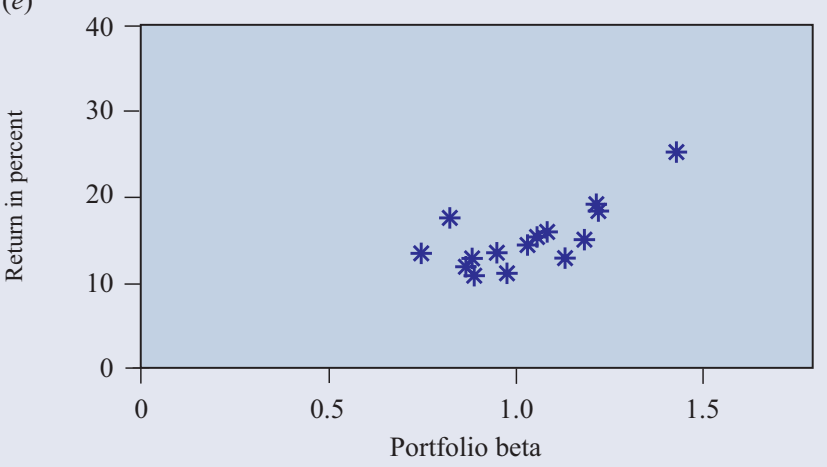

(b)

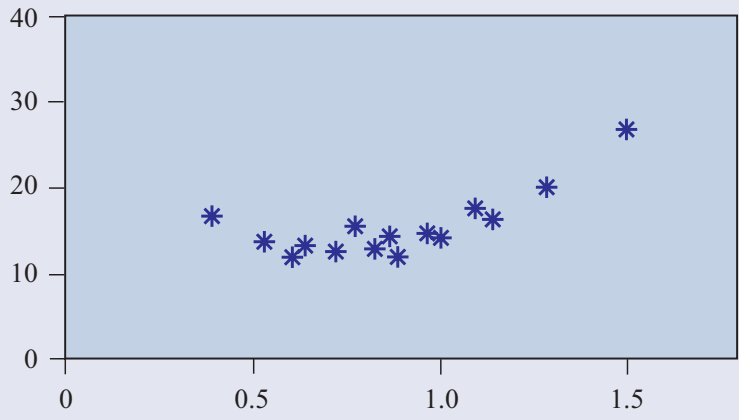

(d)

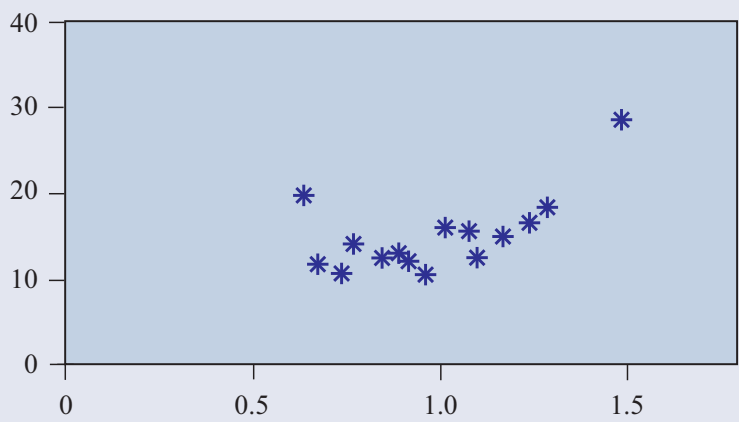

$(f)$

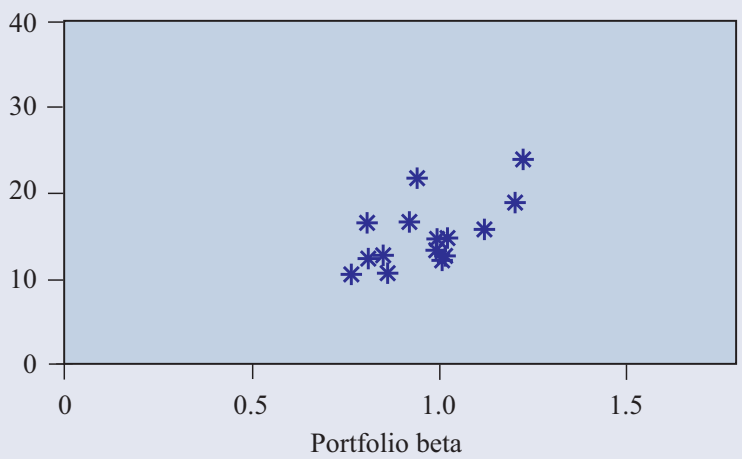

Figure 4. Average daily portfolio returns (vertical axis) versus corresponding average portfolio betas at different wavelet scales. The returns are expressed as yearly compound rate percentages for presentation purposes. The wavelet scales are the following: (a) scale 1, 2-4 day period; (b) scale 2, 4-8 day period; (c) scale 3, 8-16 day period; (d) scale 4, 16-32 day period; (e) scale 5, 32-64 day period; (f) scale 6, 64-128 day period. Notice that as the scale increases from low (a) to high (f), the relationship between the beta and the return becomes steeper.

calculating the average return from each portfolio for the next year) is repeated for the entire sample ${ }^{16}$.

When the entire sample period is covered, we have average betas for ten (and 15) portfolios (from lowest beta portfolios to the largest beta portfolios) and corresponding average returns at each wavelet scale. If the CAPM is valid, we expect a positive relationship between the average beta of each portfolio and the corresponding average return. In other words, we expect that as the average beta increases, the average return increases as well. Figure 4 plots average daily portfolio returns

${ }^{16}$ See Reinganum (1981) for a similar approach to beta estimation and testing the CAPM. (vertical axis) versus corresponding average portfolio betas at different wavelet scales. The returns are expressed as yearly compound rate percentages for presentation purposes. A visual inspection of figure 4 reveals that there is a positive relationship between the average betas of portfolios and average returns at every scale. However, we notice that the relationship between average betas and average returns seems to be nonlinear at lower scales. As the scale increases from low (figure 4(a)) to high (figure 4(f)), the relation between the beta and the return becomes steeper and the dispersion of beta values decreases. The existence of noise traders (traders selling or buying stock for non-fundamental reasons) and other anomalies such as infrequent trading and bid-ask bounce might be some of the 
Table 1. The OLS estimates of average portfolio return (dependent variable) versus average portfolio betas (independent variable) at different scales. The OLS estimate of average return versus average portfolio betas from the raw data is also reported for comparison purposes. The wavelet scales are the following: scale 1,2-4 day periods; scale 2, 4-8 day periods; scale 3, 8-16 day periods; scale 4, 16-32 day periods; scale 5, 32-64 days, and scale 6, 64-128. The results are obtained from ten different portfolios (left) and 15 different portfolios (right) constructed according to beta ranking of stocks. Both slope and intercept are multiplied by 100 for reporting purposes. One star (*) indicates that the coefficient is significant at the $10 \%$ significance level, two stars $(* *)$ at the $5 \%$ significance level and three stars $(* * *)$ at the $1 \%$ significance level.

\begin{tabular}{lcllllll}
\hline & \multicolumn{3}{c}{10 portfolios } & & \multicolumn{3}{c}{15 portfolios } \\
\cline { 2 - 3 } \cline { 6 - 8 } \cline { 6 - 8 } & Constant & Slope & $\bar{R}^{2}$ & & Constant & Slope & $\bar{R}^{2}$ \\
\hline Scale 1 & $0.039^{* * *}$ & $0.0181^{*}$ & 0.26 & & $0.040^{* * *}$ & $0.0181^{*}$ & 0.22 \\
Scale 2 & $0.028^{* *}$ & $0.0291^{* * *}$ & 0.55 & & $0.027^{* * *}$ & $0.0303^{* * *}$ & 0.51 \\
Scale 3 & $0.028^{* *}$ & $0.0285^{* *}$ & 0.42 & & $0.027^{* *}$ & $0.0293^{* *}$ & 0.36 \\
Scale 4 & 0.018 & $0.0358^{* *}$ & 0.42 & & 0.017 & $0.0370^{* *}$ & 0.36 \\
Scale 5 & 0.007 & $0.0461^{* * *}$ & 0.57 & & 0.004 & $0.0486^{* * *}$ & 0.53 \\
Scale 6 & -0.001 & $0.0566^{* *}$ & 0.32 & & -0.003 & $0.0551^{* *}$ & 0.36 \\
Raw & $0.025^{* *}$ & $0.306^{* *}$ & 0.52 & & $0.024^{* *}$ & $0.315^{* *}$ & 0.51 \\
\hline
\end{tabular}

contributing factors behind the weak relation between the portfolio return and its beta at low scales. Also notice that the portfolios in this study are equally weighted and thus give greater weight to smaller capitalized stocks. A further study with capitalization weighted portfolios in a wavelet multiscale framework may give more accurate results. It is possible that different portfolios with different capitalization structures (small caps versus large caps) would require different wavelets.

Table 1 reports the OLS estimate of the regression coefficient of average portfolio return (dependent variable) versus average portfolio betas (independent variable) at different scales for both ten and 15 portfolios. The OLS estimate of average return versus average portfolio betas from the raw data is also reported for comparison purposes. The estimation results in table 1 show that the positive relationship between the beta of each portfolio and the corresponding average return is significant at all wavelet scales. Notice that the magnitude of the regression coefficient increases as wavelet scale increases. For example, an increase in portfolio beta from $\beta=1$ to 2 results in (annual compound) a $4.8 \%$ increase in the daily portfolio return at the first wavelet scale while the same increase in portfolio beta results in (annual compound) a $15.4 \%$ increase at the sixth wavelet scale. Furthermore, the estimated regression coefficient at the first scale is significantly different from the estimated regression coefficient at the sixth scale $^{17}$. In other words, the predictions of the CAPM model are more relevant for investors with medium long run horizon as compared to those with short time horizons since the higher wavelet scale contains low frequency (long term) dynamics.

\section{Conclusions}

In this paper, we propose a new approach in estimating the systematic risk or the beta of an asset in a CAPM. The proposed method is based on a wavelet multiscaling approach that decomposes a given time series on a scale-by-scale basis.

17 The estimated regression coefficient in table 1 is 0.000181 at scale 1 (for both 10 and 15 portfolios). This means that a one-unit increase in portfolio beta (from $\beta=1$ to 2 ) results in a 0.000181 unit increase in average daily return. Assuming 260 business days, the corresponding annual compound increase is $4.8 \%$ since $(1+0.000181)^{260}=1.0482$.
At each scale, the wavelet variance of the market return and the wavelet covariance between the market return and a portfolio are calculated to obtain an estimate of the portfolio's beta. The empirical results show that the relationship between the return of a portfolio and its beta becomes stronger as the scale increases. In other words, the predictions of the CAPM model are more relevant at medium long run as compared to short time horizons.

The issues surrounding the testing of the CAPM require a more detailed analysis than the scope of this paper. It is possible to separate the signal from the noise with well defined criteria at different wavelet timescales, and show the effect of the low signal-to-noise ratio at lower scales on testing the CAPM. In other words, exploring the effects of low signal-tonoise ratios at lower scales on the power of tests commonly employed in testing the CAPM is a promising line of research. Another issue in testing the CAPM is the 'size effect'. The portfolios in this study are equally weighted and thus give greater weight to smaller capitalized stocks. It would be interesting to pursue further study with capitalization weighted portfolios in a wavelet multiscale framework proposed in this study. It is quite possible that different portfolios with different capitalization structures (small caps versus large caps) would require different wavelets. That is, there is no reason to employ a particular wavelet for every stock or portfolio. We leave these for further study.

\section{Acknowledgments}

Ramazan Gençay gratefully acknowledges financial support from the Swiss National Science Foundation under NCCRFinrisk, Natural Sciences and Engineering Research Council of Canada and the Social Sciences and Humanities Research Council of Canada. We thank Abdurrahman Ulugülyağcı for research assistance. Faruk Selçuk greatly acknowledges financial support from the Colorado College Social Science Executive Division Research and Development Fund. 


\section{References}

Bekaert G and Harvey C R 1995 Time-varying world market integration J. Finance 50 403-444.

Bekaert G and Harvey C R 1997 Emerging equity market volatility J. Financial Economics 43 29-78

Bjornson B, Kim H S and Lee K 1999 Low and high frequency macroeconomic forces in asset pricing $Q$. Rev. Economics Finance 39 77-100

Black F 1972 Capital market equilibrium with restricted borrowing J. Business 45 444-54

Black F, Jensen M and Scholes M 1972 Capital asset pricing model: some empirical tests Studies in the Theory of Capital Markets ed M Jensen (New York: Praeger)

Blanchard O J and Fischer S 1989 Lectures on Macroeconomics (Cambridge, MA: MIT Press)

Brailsford T J and Faff R W 1997 Testing the conditional CAPM and the effect of intervaling: a note Pacific-Basin Finance J. 5 $527-37$

Brailsford T J and Josev T 1997 The impact of return interval on the estimation of systematic risk Pacific-Basin Finance J. 5 353-72

Campbell J Y 2000 Asset pricing at the millennium J. Finance $\mathbf{5 5}$ $1515-67$

Cochrane J H 1999 New facts in finance Economic Perspectives 23 59-78 (Federal Reserve Bank of Chicago)

Cohen K, Hawawini G, Mayer S, Schwartz R and Whitcomb D 1986 The Microstructure of Securities Markets (Sydney: Prentice-Hall)

Daubechies I 1992 Ten Lectures on Wavelets (Philadelphia, PA: SIAM)

Fama E F 1980 Stock returns, expected returns and real activity J. Finance 45 1089-107

Fama E F 1981 Stock returns, real activity, inflation and money Am. Econ. Rev. 71 545-65

Fama E F and MacBeth J 1973 Risk, return and equilibrium: empirical tests J. Political Economy 71 607-36

Frankfurter G, Leung W and Brockman W 1994 Compounding period length and the market model J. Economics Business 46 179-93

Garcia R and Ghysels E 1998 Structural change and asset pricing in emerging markets J. Int. Money Finance 17 455-73

Gençay R, Selçuk F and Whitcher B 2001a An Introduction to Wavelets and Other Filtering Methods in Finance and
Economics (San Diego, CA: Academic)

Gençay R, Selçuk F and Whitcher B 2001b Differentiating intraday seasonalities through wavelet multi-scaling Physica A 289 $543-56$

Gençay R, Selçuk F and Whitcher B 2001c Scaling properties of foreign exchange volatility Physica A 289 249-66

Handa P, Kothari S P and Wasley C 1989 The relation between the return interval and betas: implications for the size effect J. Financial Economics 23 79-100

Handa P, Kothari S P and Wasley C 1993 Sensitivity of multivariate tests of the capital asset pricing to the return interval measurement J. Finance 48 15-43

Harvey C R 1989 Time-varying conditional covariances in tests of asset pricing models J. Financial Economics 24 289-317

Harvey C R 1991 The world price of covariance risk, J. Finance XLVI 111-57

Hawawini G 1983 Why beta shifts as the return interval changes J. Financial Analysts 39 73-7

Levhari D and Levy H 1977 The capital asset pricing model and the investment horizon Rev. Economics Statistics 59 92-104

Lintner J 1965 The valuation of risky assets and the selection of risky investments in stock portfolios and capital budgets Rev. Economics Statistics 47 13-37

Mallat S 1998 A Wavelet Tour of Signal Processing (San Diego, CA: Academic)

Ramsey J B 1999 The contribution of wavelets to the analysis of economic and financial data Phil. Trans. R. Soc. A $\mathbf{3 5 7}$ 2593-606

Ramsey J B and Lampart C 1998a The decomposition of economic relationships by timescale using wavelets: expenditure and income Studies Nonlinear Dynamics Economics $323-42$

Ramsey J B and Lampart C 1998b Decomposition of economic relationships by timescale using wavelets: money and income Macroeconomics Dynamics 2 49-71

Ramsey J B and Zhang Z 1997 The analysis of foreign exchange data using waveform dictionaries J. Empirical Finance 4 341-72

Reinganum M R 1981 A new empirical perspective on the CAPM J. Financial Quant. Anal. 16 439-62

Scholes M and Williams J 1977 Estimating betas from non-synchronous data J. Financial Economics 5 309-27

Sharpe W 1964 Capital asset prices: a theory of market equilibrium under conditions of risk $J$. Finance 19 425-42 